\title{
EDITORIAL
}

\section{REFLEXÕES SOBRE A PRODUÇÃO E A DIVULGAÇÃO DO CONHECIMENTO CIENTÍFICO DA ENFERMAGEM}

Maria Helena Palucci Marziale ${ }^{1}$

Autor(a) correspondente: Maria Helena Palucci Marziale. Avenida Bandeirantes 3.900, Campus Universitário USP, Ribeirão Preto, São Paulo, Brasil. CEP 14040-902. 55-16-33154321, marziale@eerp.usp.br

\section{Como citar esse artigo}

Marziale MHP. Reflexões sobre a produção e a divulgação do conhecimento científico da Enfermagem. Advances in Nursing [Internet]. 2019 [cited ano mes dia];1(1):página.

Inicialmente, parabenizamos o Departamento de Enfermagem da Universidade Estadual de Londrina e o seu Programa de Pós-Graduação em Enfermagem pela criação e lançamento da ADVANCES IN NURSING AND HEALTH $(\mathrm{ANH})$, revista que tem como missão publicar resultados de estudos que contribuam para a construção do conhecimento científico e tecnológico em Enfermagem e áreas afins. Uma conquista resultante do esforço de professores, estudantes e funcionários que, há tempos, têm se dedicado com afinco à formação de profissionais enfermeiros pesquisadores e, generosamente, expandem essa colaboração para divulgar os resultados das pesquisas desenvolvidas pelos enfermeiros e profissionais da área da saúde do Brasil e do mundo, ampliando, assim, a contribuição desta instituição de ensino e pesquisa para o avanço do conhecimento científico e para a qualificação da prática profissional de Enfermagem.

Nesse editorial, abordamos aspectos da produção e da divulgação do conhecimento produzido pela enfermagem do Brasil e convidamos os leitores à reflexão sobre demandas da área.

${ }^{1}$ Enfermeira. Professora Titular da Escola de Enfermagem de Ribeirão Preto da Universidade de São Paulo. Diretora. Ribeirão Preto, São Paulo, Brasil. marziale@eerp.usp.br. ORCID iD: https://orcid.org/0000-0003-2790-3333 
Observa-se que a produção e a divulgação das pesquisas da Enfermagem produzidas no Brasil muito avançaram nas últimas décadas tanto na quantidade quanto na qualidade de seus produtos devido ao trabalho efetivo de instituições formadoras, em especial dos programas de pós-graduação, dos grupos de pesquisa e das instituições editoras dos periódicos científicos que, mediante movimentos colaborativos contribuíram para a profissionalização de equipes editoriais. Assim, merece destaque a atuação da $\mathrm{Bi}$ blioteca Virtual de Saúde - Enfermagem, da Coleção Revistas de Enfermagem - REVENF, do Fórum de Editores de Revistas da Associação Brasileira de Enfermagem e da Rede Iberoamericana de Editoração Científica em Enfermagem - REDEDIT. Porém, ainda há muito a fazer.

Dentre as demandas que nos são apresentadas, destacamos aquelas oriundas da Campanha Nursing Now que têm por objetivo auxiliar os enfermeiros e parteiras a enfrentar os desafios de saúde do século XXI e a maximizar a sua contribuição para alcançar o objetivo da Cobertura Universal de Saúde. A referida campanha visa assegurar-Ihes maior participação na formulação de políticas públicas de saúde, incentivar maior investimento na força de trabalho da enfermagem, recru- tar mais enfermeiros para ocuparem cargos de liderança, realizar pesquisas que ajudem a determinar onde os enfermeiros podem gerar maior impacto[1].

Porém, mais do que uma estratégia de divulgação para chamar a atenção da sociedade global para a profissão, essa campanha nos leva a refletir sobre a qualidade da formação, da assistência prestada e das pesquisas desenvolvidas e como os seus resultados estão impactando a sociedade e a ciência.

No Brasil, os indicadores bibliométricos revelam que as pesquisas na área da Enfermagem têm elevado número de produções, porém, apresentam um expressivo número de estudos descritivos, de fraca evidência científica, os quais que restringem à utilização e à translação de seus resultados para a prática e o avanço do conhecimento científico. Assim, a demanda apresentada aos programas de pós-graduação é mudar o foco no ensinar "fazer pesquisa" para o de ensinar "fazer e utilizar a pesquisa, avaliando barreiras e facilitadores para o uso de seus resultados" e incluir no planejamento dos estudos o modo com que os resultados serão divulgados e consumidos.

Demandas também nos são apresentadas como diretivas de pesquisas. A Agen- 
da de Sustentabilidade Ambiental - Agenda 2030, formulada pela Organização das Nações Unidas(2), é composta por 17 Objetivos de Desenvolvimento Sustentável (ODS) e 169 metas que mesclam as dimensões econômica, social e ambiental e apresentam a lista de tarefas a serem cumpridas pelos governos, sociedade, empresas, academia e cidadãos para melhorar a vida das pessoas. Os enfermeiros podem contribuir para o cumprimento não apenas do ODS 3 - Saúde e bem-estar (assegurar uma vida saudável e promover o bem-estar para todos, em todas as idades), mas também em ações dos outros ODS que estão propostos de maneira integrada, pois, os fatores educação, trabalho, gênero e etnia exercem influência direta no estado de saúde das pessoas, e os determinantes sociais são essenciais ao fomento das capacidades humanas e ao desenvolvimento sustentável. A Agenda de Saúde Sustentável para as Américas 2018-2030 - ASSA 2030(3), por sua vez, agrega as especificidades das regiões das Américas e, portanto, também nos direciona às necessidades locais a serem consideradas nas pesquisas desenvolvidas, pois os seus resultados estruturam a prática de Enfermagem e estabelecem intrínseca relação na formação de recursos humanos.

Em relação aos resultados das pesquisas, diante das profundas mudanças na comunicação e divulgação científica, é preciso ampliar as estratégias para divulgá-los. Os resultados dos estudos continuam sendo divulgados pelas revistas científicas, e o processo de revisão por pares qualifica o texto, certifica a qualidade científica do estudo, agrega valor ao artigo e por isso são reconhecidos e valorizados pela comunidade cientifica. Porém, existem outros meios de divulgação que, além dos periódicos científicos, podem ajudar a divulgar os resultados da pesquisa à comunidade e à sociedade em geral, entre os quais as mídias sociais e os repositórios preprints e postprints cujos textos não passam por revisão por pares, mas têm a qualificação do texto feita no processo após a sua publicação no repositório.

Assim, finalizamos esta mensagem parabenizando enfermeiros, pesquisadores, professores e orientadores dos cursos de pós-graduação e editores das revistas de Enfermagem pela trajetória percorrida, deixando os pontos aqui elencados para reflexão e discussão conjunta em prol de novas conquistas e avanços. 


\section{REFERÊNCIAS}

1. Kennedy A. Onde quer que você encontre enfermeiros no mundo, você encontrará líderes. Rev Latino-Am Enferm [Internet]. 2019 [citado 2019 Jun 09]; 27: e3181. Disponível em: http://www.scielo.br/ scielo. php?script $=$ sci_arttext\&pid $=$ S010411692019000100204\&/ng=pt doi: http:// dx.doi.org/10.1590/1518-8345.0000.3181.

2. Naciones Unidas. Transformar nuestro mundo: la Agenda 2030 para el Desarrollo Sostenible. Septuagésimo período de sesiones de la Asamblea General, resolución A/RES/70/1. 2015. [cited 2019 Jun 09]. Disponible: https://documents-dds-ny.un.org/doc/ UNDOC/GEN/N15/291/93/PDF/N1529193. pdf?OpenElement.

3. Organización Panamericana de lá Salud. Agenda de salud sostenible para las Américas 2018-2030 [Internet]. Washington, DC; 2017 [cited 2019 Jun 09]. Disponible https://www. paho.org/hq/index.php?option=com_conte nt\&view $=$ article\&id=13246: health-agendaamericas\&Itemid $=42349 \& / a n g=e s$ 